\title{
A Polymerizable Hydrophobically Modified Ethoxylated Urethane Acrylate Polymer: Synthesis and Viscoelastic Behavior in Aqueous Systems
}

Tao Guan, ${ }^{1}$ Zhukang Du, ${ }^{2 *}$ Jun Peng, ${ }^{1}$ Dongli Zhao, ${ }^{1}$ Ning Sun ${ }^{2}$ and Biye Ren ${ }^{1 *}$

${ }^{1}$ School of Materials Science and Engineering, South China University of Technology, Guangzhou 510640, China

${ }^{2}$ South China Advanced Institute for Soft Matter Science and Technology, South China University of Technology, Guangzhou 510641, China

${ }^{3}$ Department of Material Technology, Jiangmen Polytechnic, Jiangmen 529090, China

* E-mail: duzhukang1991@163.com (Z.D.); mcbyren@scut.edu.cn (B.R.). 

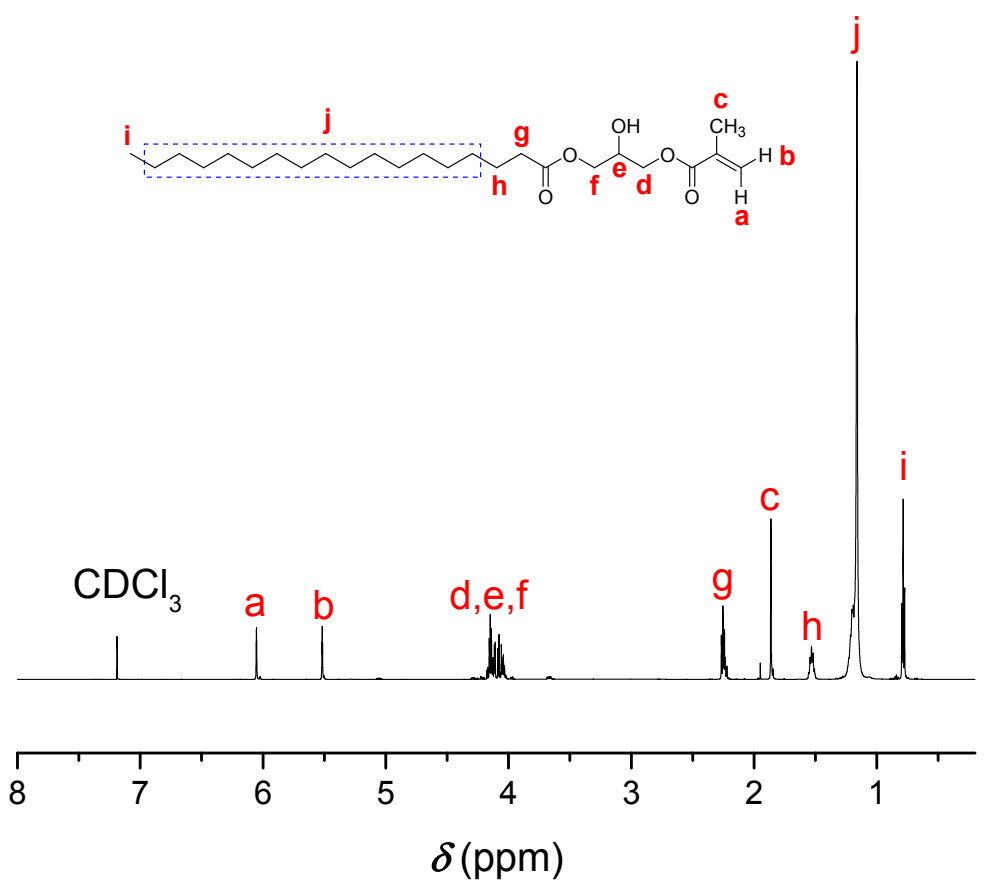

Figure S1. ${ }^{1} \mathrm{H}-\mathrm{NMR}$ spectrum of C18-GMA-OH end capper in $\mathrm{CDCl}_{3}$.

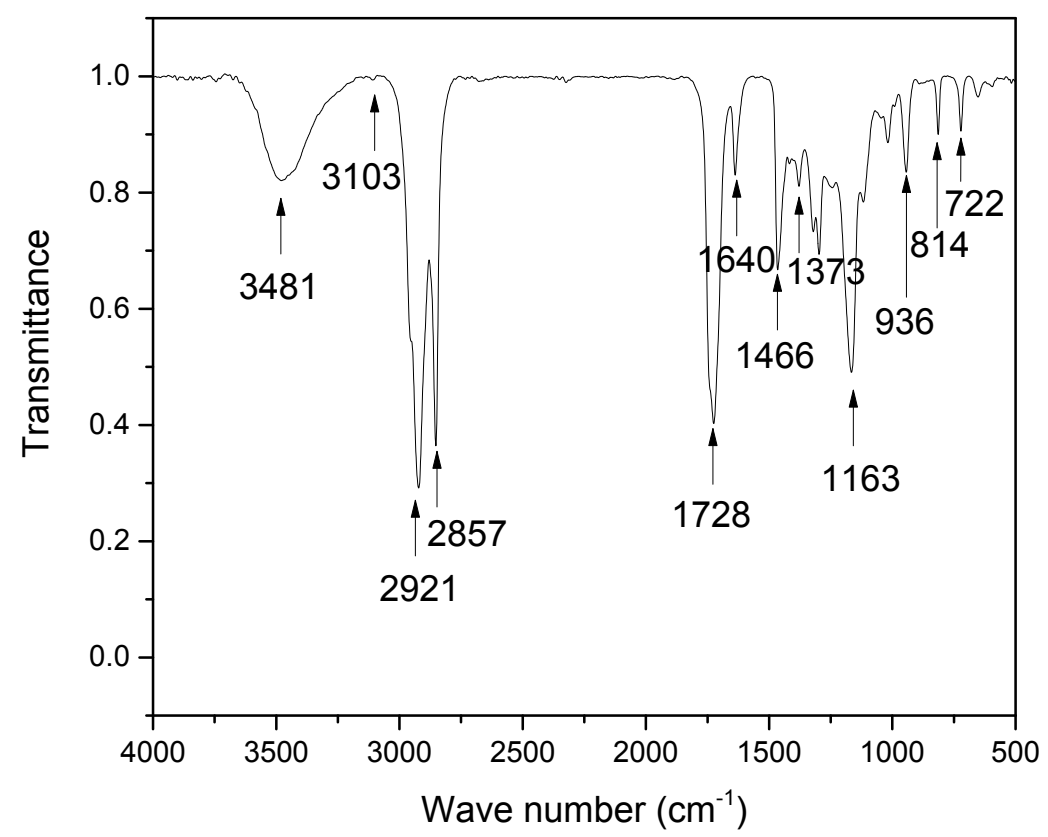

Figure S2. FTIR spectrum of C18-GMA-OH end capper. 


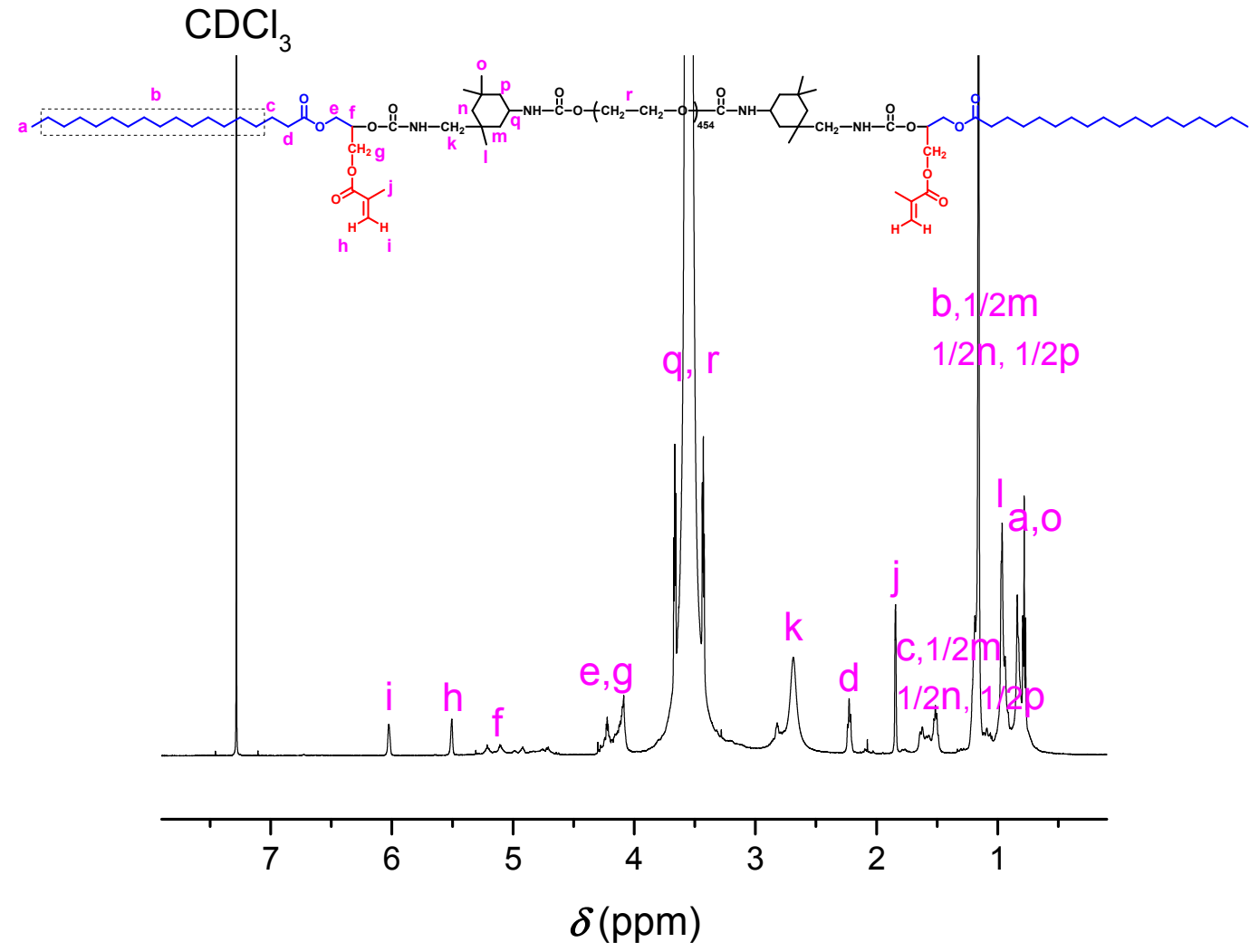

Figure S3. ${ }^{1} \mathrm{H}-\mathrm{NMR}$ spectrum of Acrylic-HEUR polymer in $\mathrm{CDCl}_{3}$.

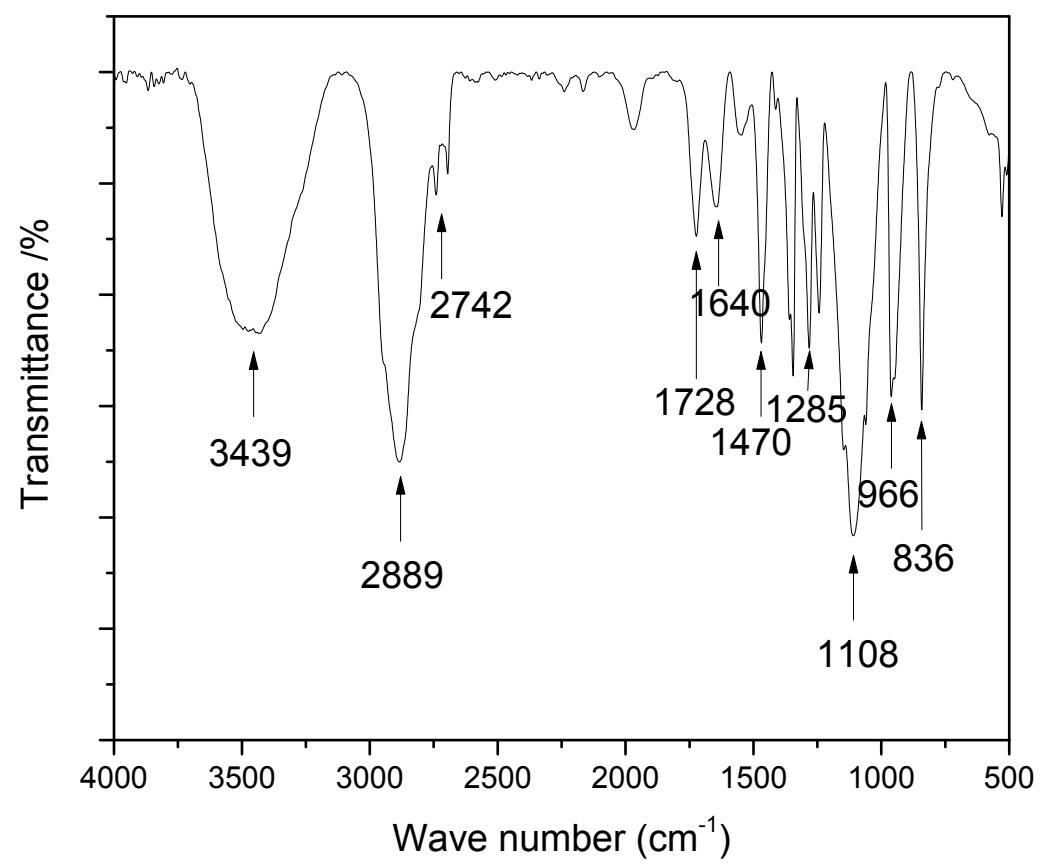

Figure S4. FTIR spectrum of Acrylic-HEUR polymer. 


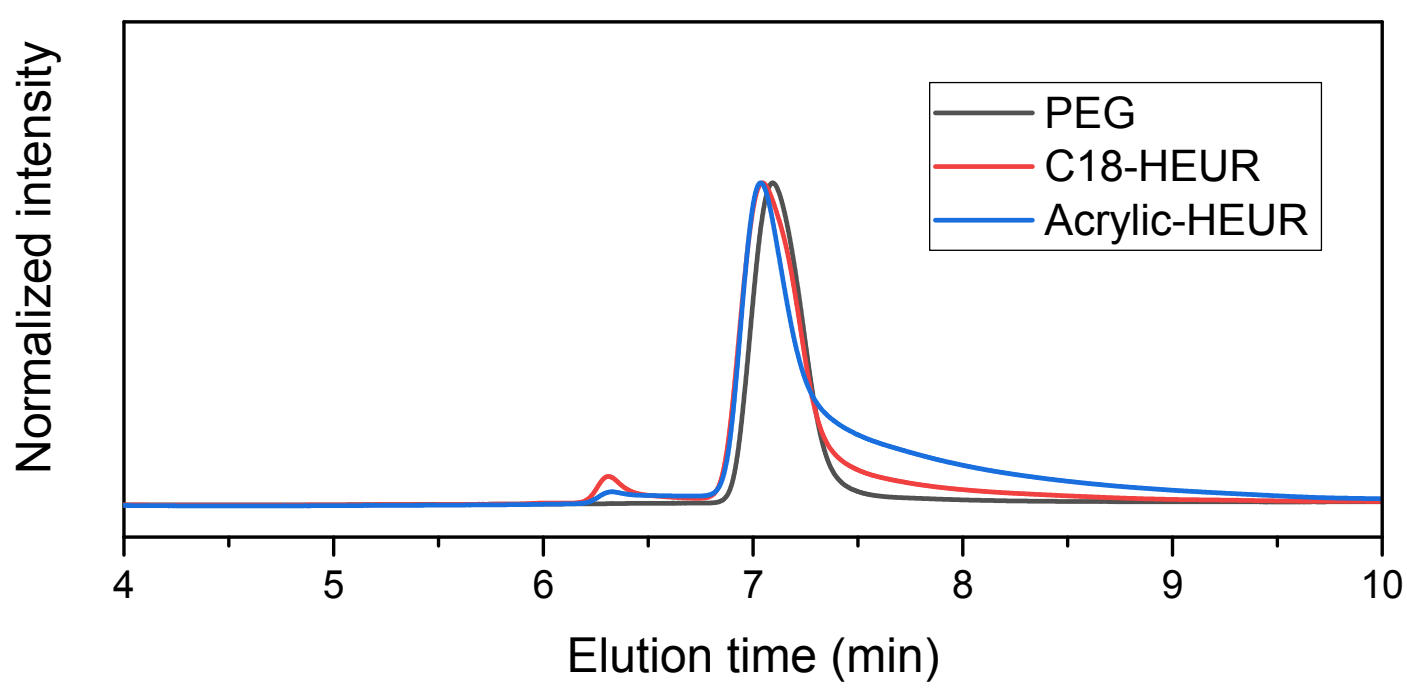

Figure S5. GPC chromatograms of pure PEG, Acrylic-HEUR and C18-HEUR.

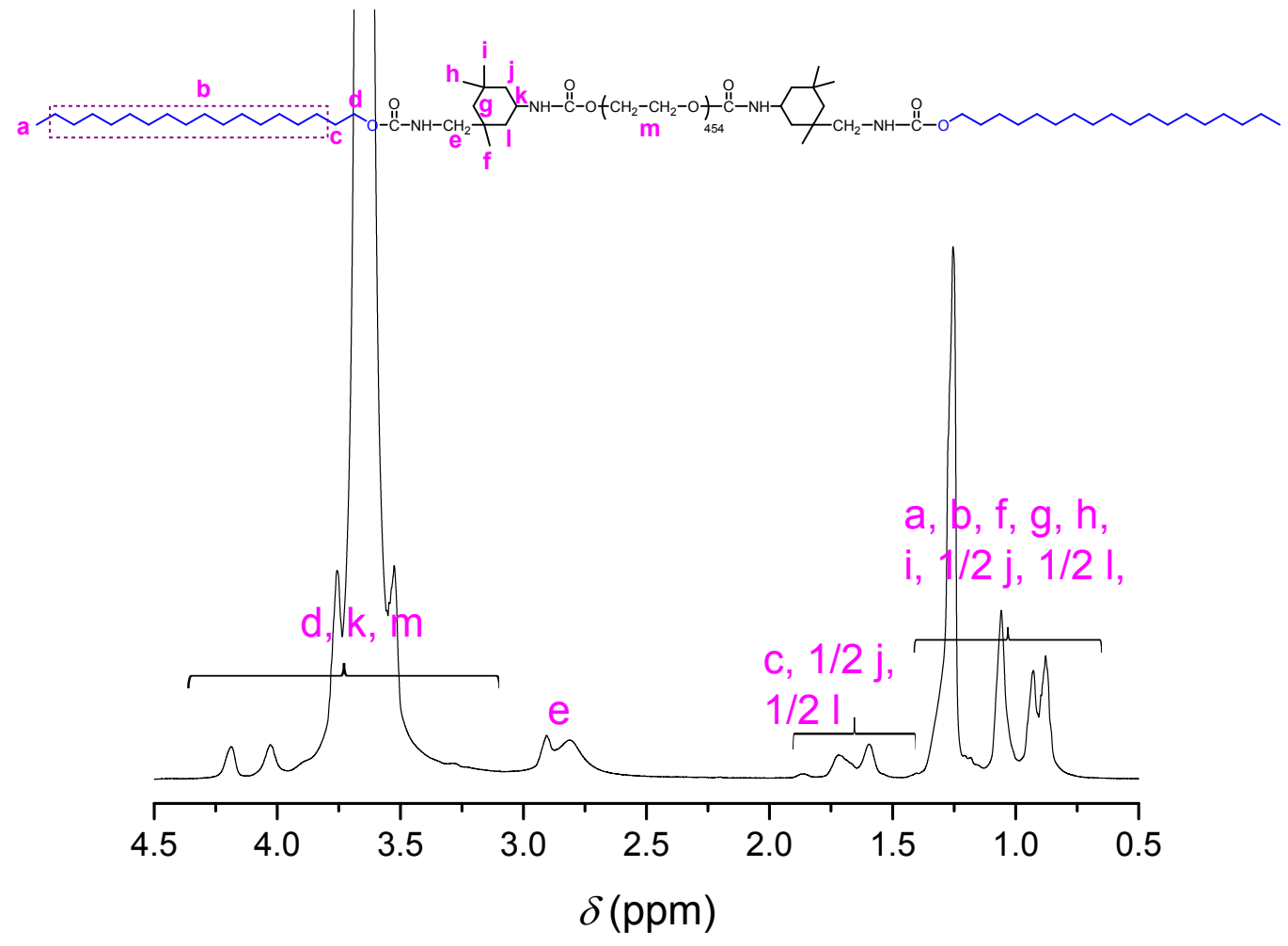

Figure S6. ${ }^{1} \mathrm{H}-\mathrm{NMR}$ spectrum of $\mathrm{C} 18$-HEUR polymer in $\mathrm{CDCl}_{3}$. 


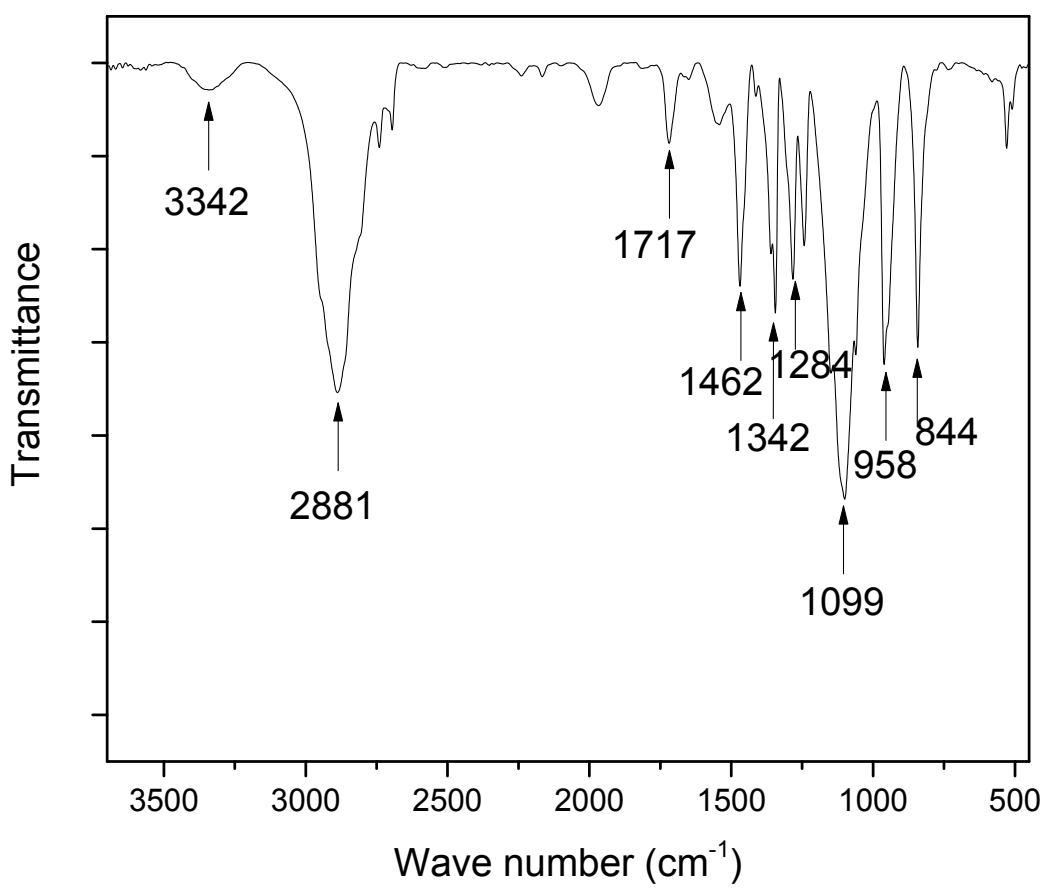

Figure S7. FTIR spectrum of C18-HEUR polymer. 


\section{Calculation of end capping ratio $(E C R)$ and $M_{\mathrm{n}}$ for Acrylic-HEUR and C18-HEUR}

\section{polymer from ${ }^{1} \mathrm{H}-\mathrm{NMR}$}

The $E C R$ is defined as the degree of end capping reaction for the urethane pre-polymer and it is especially ketal to guarantee association and bridge of HEUR polymer in solution. The calculation method here is mainly referred a typically reported ${ }^{1} \mathrm{H}-\mathrm{NMR}$ method $^{1-3}$ as displayed in following equations:

$$
\begin{gathered}
I_{(0.8-1.38)}=31 N_{\text {end capper }}+12 N_{I P D I} \\
I_{(1.38-2.23)}=7 N_{\text {end capper }}+3 N_{I P D I} \\
I_{(2.23-4.3)}=1818 N_{P E G}+4 N_{\text {end capper }}+3 N_{I P D I} \\
N_{I P D I}=N_{P E G}+1
\end{gathered}
$$

Where $I$ represent the integration intensity of proton signals at indicated chemical shift range, $N_{\mathrm{PEG}}, N_{\mathrm{IPDI}}, N_{\text {end capper }}$ are respectively defined as the numbers of these moieties per Acrylic-HEUR polymer chain. According to equations (1-4), we can calculate the real number of $N_{\text {PEG }}, N_{\text {IPDI }}, N_{\text {end capper }}$ per Acrylic-HEUR polymer chain and the end capping ratio $(E C R)$ can be calculated from following equation:

$$
E C R=\frac{N_{\text {end capper }}}{2} \times 100 \%
$$

besides, the number average molecular weight $\left(M_{\mathrm{n}}\right)$ of the Acrylic-HEUR polymer can also be calculated using above three parameters, the calculation equation is expressed as follows:

$$
M_{n}(N M R)=20000 N_{P E G}+222 N_{I P D I}+427 N_{\text {end capper }}
$$

According to the ${ }^{1} \mathrm{H}-\mathrm{NMR}$ integration intensity combining with equations from (1)-(4), 
the three parameters including $N_{\mathrm{PEG}}, N_{\mathrm{IPDI}}, N_{\text {end capper }}$ can be obtained. The $M_{\mathrm{n}}$ and $E C R$ of C18-HEUR can be figured out following a similar way to Acrylic-HEUR, the calculation equations are as follows:

$$
\begin{gathered}
I_{(0.8-1.45)}=31 N_{\text {end capper }}+13 N_{I P D I} \\
I_{(1.45-2.23)}=2 N_{\text {end capper }}+2 N_{I P D I} \\
I_{(2.23-4.3)}=1818 N_{P E G}+2 N_{\text {end capper }}+3 N_{I P D I} \\
N_{I P D I}=N_{P E G}+1
\end{gathered}
$$

The ECR of C18-HEUR can be obtained through the equation (5) as well, and the $M_{\mathrm{n}}$ can be calculated following the equation (11):

$$
M_{n}(N M R)=20000 N_{P E G}+222 N_{I P D I}+270 N_{\text {end capper }}
$$

The results are summarized as follows in table S1.

Table S1. ${ }^{1} \mathrm{H}-\mathrm{NMR}$ characterization of Acrylic-HEUR and C18-HEUR polymers

\begin{tabular}{lccccc}
\hline Polymers & $N_{\text {PEG }}$ & $N_{\text {IPDI }}$ & $N_{\text {end capper }}$ & $M_{\mathrm{n}}(\mathrm{NMR})$ & $E C R$ \\
\hline Acrylic-HEUR & 0.98 & 1.98 & 1.96 & 20800 & $98 \%$ \\
C18-HEUR & 0.95 & 1.95 & 1.92 & 20000 & $96 \%$ \\
\hline
\end{tabular}




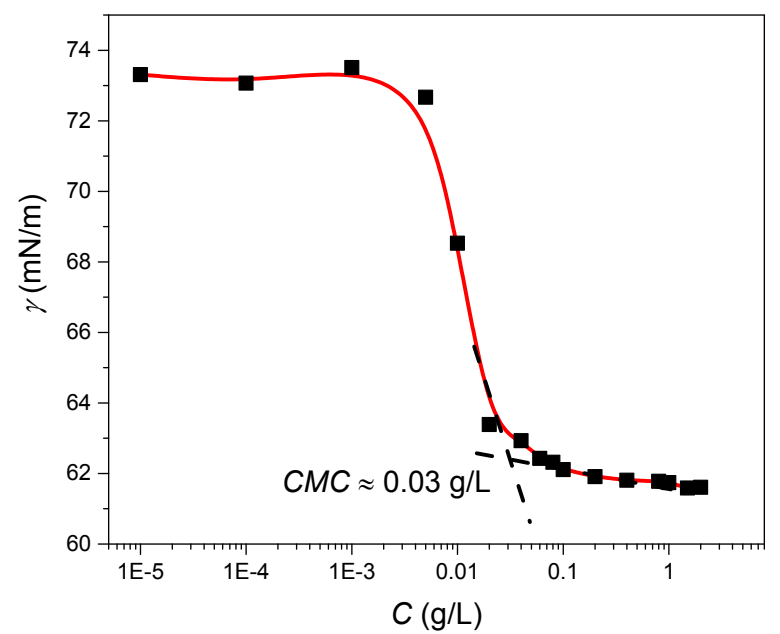

Figure S8. Plot of solution surface tensions against Acrylic-HEUR concentrations $(C)$ at $25^{\circ} \mathrm{C}$.

(a)

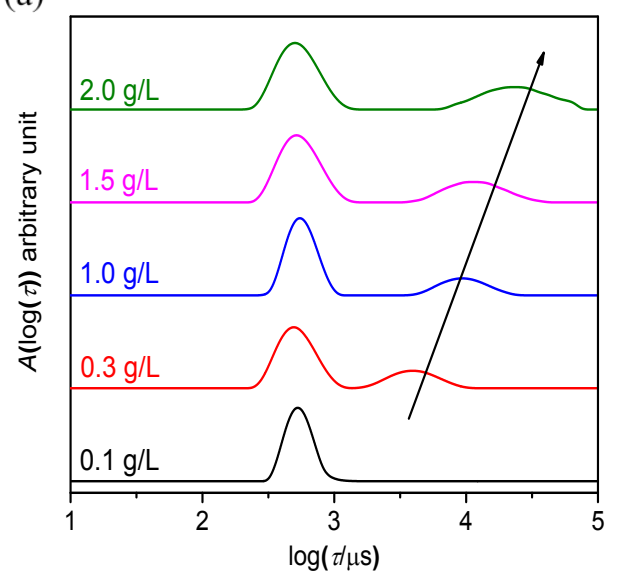

(b)

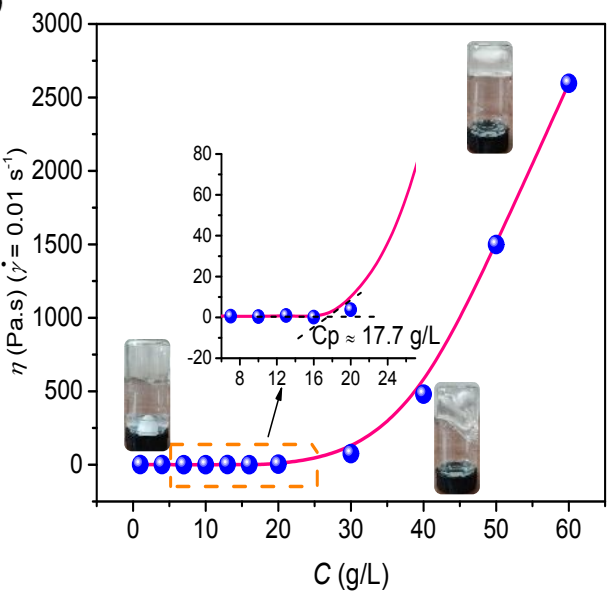

(c)

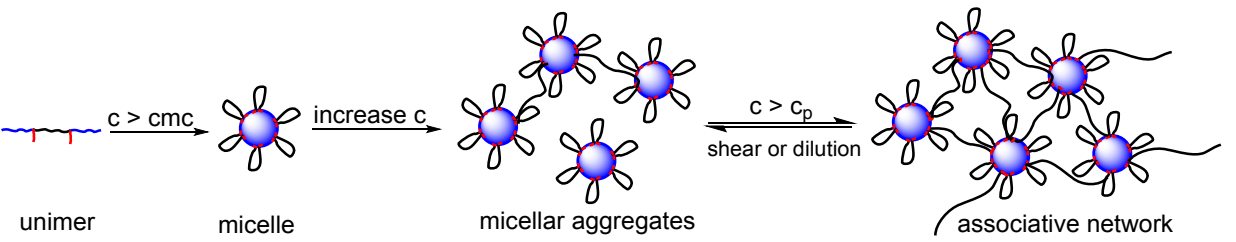

Figure S9. (a) Relaxation time distribution obtained from DLS measurements for a series of dilute Acrylic-HEUR aqueous solutions at $25^{\circ} \mathrm{C}$. (b) Plot of low/zero shear viscosity $\left(\eta_{0}\right)$ at $\dot{\gamma}$ $=0.01 \mathrm{~s}^{-1}$ against Acrylic-HEUR solution concentration $(C)$ at $25^{\circ} \mathrm{C}$. (c) Schematic illustrations of the association behavior of Acrylic-HEUR in aqueous solution as the solution concentration $C$ progresses. 


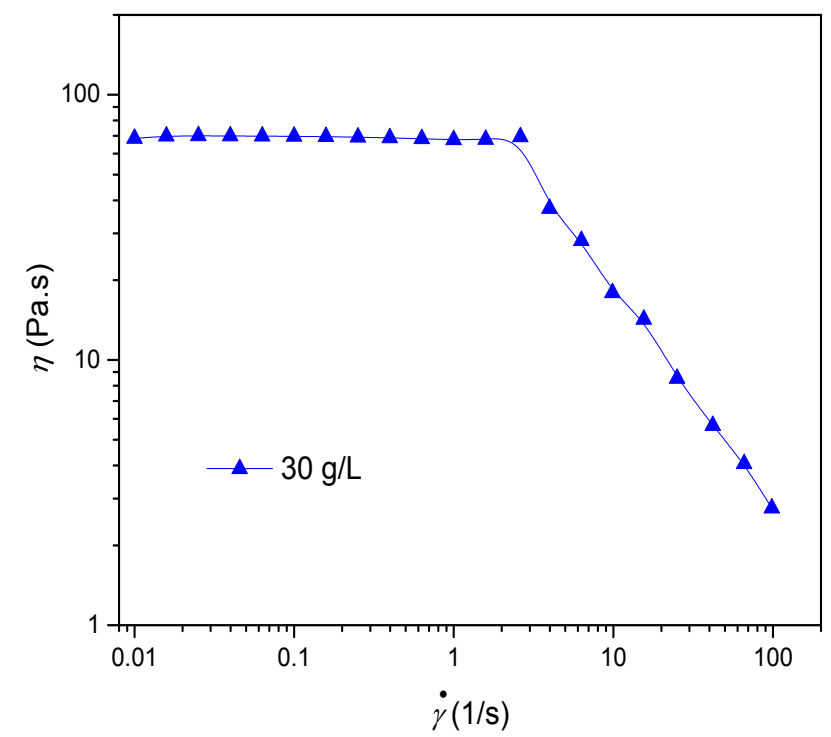

Figure S10. Plot of steady shear viscosity against shear rate $\dot{\gamma}$ for $30 \mathrm{~g} / \mathrm{L}$ C18-HEUR aqueous solutions at $25^{\circ} \mathrm{C}$.

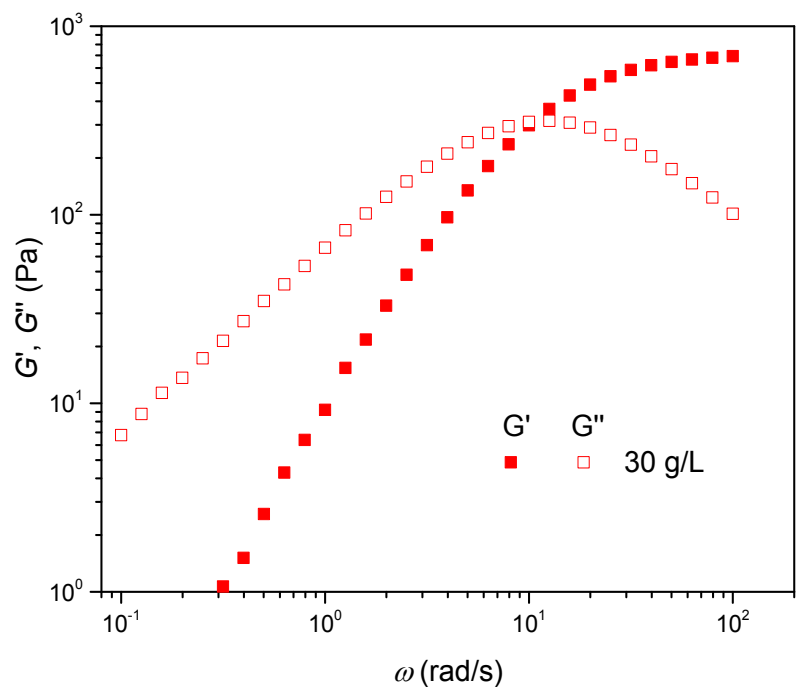

Figure S11. Oscillatory shear measurement for $30 \mathrm{~g} / \mathrm{L} \mathrm{C18-HEUR} \mathrm{aqueous} \mathrm{solutions} \mathrm{at} 25^{\circ} \mathrm{C}$. 
(a)

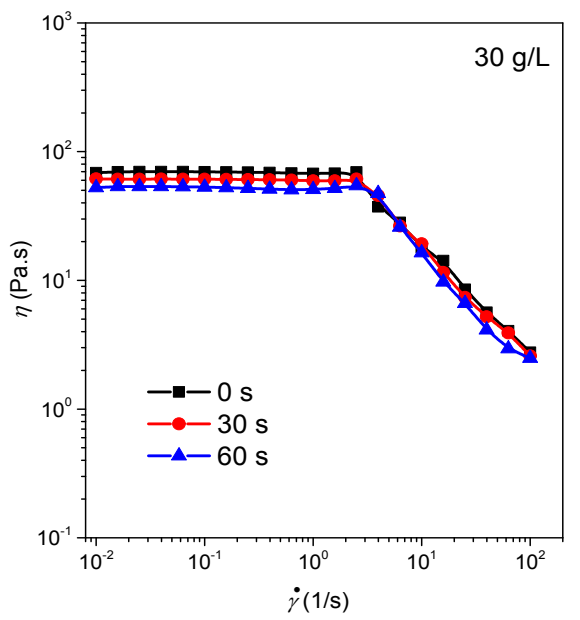

(b)

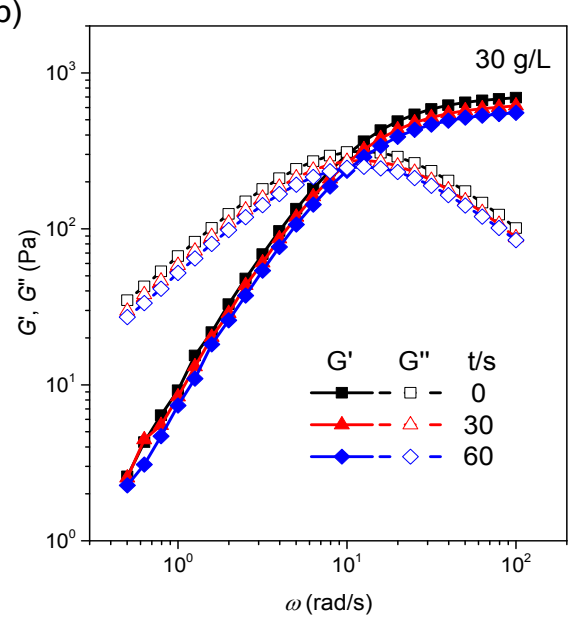

Figure S12. Steady shear (a) and oscillatory shear (b) measurements for $30 \mathrm{~g} / \mathrm{L}$ C18-HEUR aqueous solution with 1173 addition at $25^{\circ} \mathrm{C}$ upon exposure to UV irradiation for $0 \mathrm{~s}, 30 \mathrm{~s}$ and $60 \mathrm{~s}$, respectively.

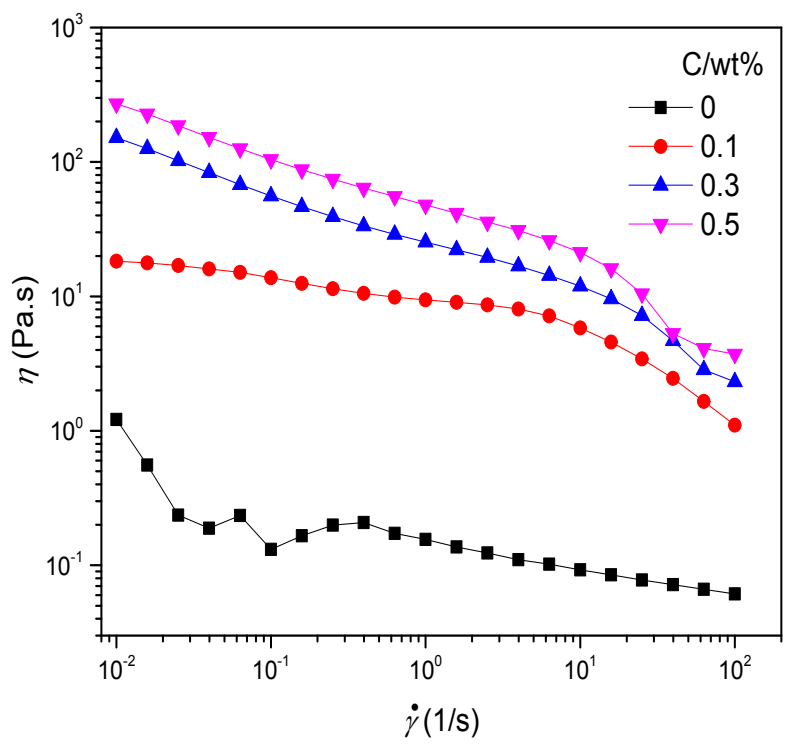

Figure S13. Plot of shear viscosity $\eta$ vs shear rate $\dot{\gamma}$ for the WUV 47 emulsion thickened by C18-

HEUR polymer at $25^{\circ} \mathrm{C}$. 


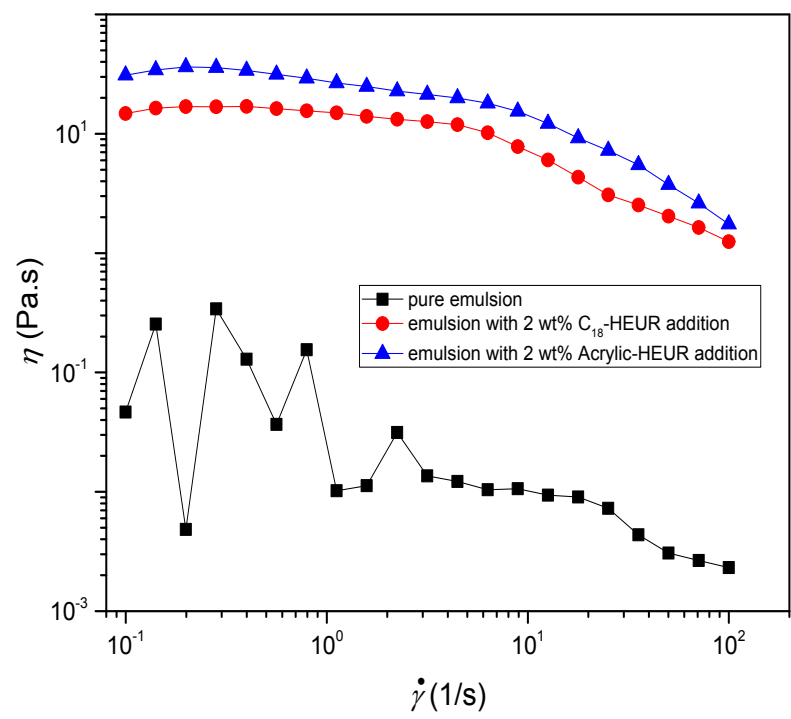

Figure S14. Plot of shear viscosity $\eta$ vs shear rate $\dot{\gamma}$ for the WUV emulsion with a solid content of $4.7 \mathrm{wt} \%$ thickened by $2 \mathrm{wt} \%$ of C18-HEUR and Acrylic-HEUR polymer at $25{ }^{\circ} \mathrm{C}$.

\section{Reference}

1. Xu, B.; Yekta, A.; Li, L.; Masoumi, Z.; Winnik, M. The Functionality of Associative Polymer Networks: The Association Behavior of Hydrophobically Modified Urethane-Ethoxylate (HEUR) Associative Polymers in Aqueous Solution. Colloids Surf., A 1996, 112 (2-3), 239-250.

2. Peng, J.; Dong, R.; Ren, B.; Chang, X.; Tong, Z. Novel Hydrophobically Modified Ethoxylated Urethanes End-Capped by Percec-Type Alkyl Substituted Benzyl Alcohol Dendrons: Synthesis, Characterization, and Rheological Behavior. Macromolecules 2014, 47 (17), 5971-5981.

3. Du, Z.; Wang, F.; Chang, X.; Peng, J.; Ren, B. Influence of Substituted Structure of Percec-Type Mini-Dendritic End Groups on Aggregation and Rheology of Hydrophobically Modified Ethoxylated Urethanes (HEURs) in Aqueous Solution. Polymer 2018, 135, 131-141. 